\title{
FGF-dependent Notch signaling maintains the spinal cord stem zone
}

\author{
Jun Akai, Pam A. Halley, and Kate G. Storey ${ }^{1}$ \\ Division of Cell and Developmental Biology, Faculty of Life Sciences, University of Dundee, Dundee DD1 5EH, \\ United Kingdom
}

\begin{abstract}
Generation of the spinal cord relies on proliferation of undifferentiated cells located in a caudal stem zone. Although fibroblast growth factor (FGF) signaling is required to maintain this cell group, we do not know how it controls cell behavior in this context. Here we characterize an overlooked expression domain of the Notch ligand, Delta1, in the stem zone and demonstrate that this constitutes a proliferative cell group in which Notch signaling is active. We show that FGF signaling is required for expression of the proneural gene cash4 in the stem zone, which in turn induces Delta1. We further demonstrate that Notch signaling is required for cell proliferation within the stem zone; however, it does not regulate cell movement out of this region, nor is loss of Notch signaling sufficient to drive neuronal differentiation within this tissue. These data identify a novel role for the Notch pathway during vertebrate neurogenesis in which signaling between high Delta1-expressing cells maintains the neural precursor pool that generates the spinal cord. Our findings also suggest a mechanism for the establishment of the cell selection process, lateral inhibition: Mutual inhibition between Delta/Notch-expressing stem zone cells switches to single Delta1-presenting neurons as FGF activity declines in the newly formed neuroepithelium.
\end{abstract}

[Keywords: Notch signaling; FGF signaling; proneural genes; spinal cord; stem cells; lateral inhibition]

Supplemental material is available at http://www.genesdev.org.

Received June 27, 2005; revised version accepted September 22, 2005.

The vertebrate spinal cord is generated progressively as the body axis extends caudally. This process relies on the provision of new cells from a unique region of the neural plate known as the caudal neural plate or stem zone and also on convergent extension movements within the newly generated neuroepitheluim (Mathis et al. 2001; Diez del Corral and Storey 2004). Cell labeling experiments demonstrate the presence of a resident cell population in the stem zone in both chick and mouse embryos (Brown and Storey 2000; Mathis and Nicolas 2000; Mathis et al. 2001). Furthermore, in the mouse, there is also evidence for a stem cell mode of division taking place in this region (Mathis and Nicolas 2000) and this has now also been observed in the chick (S.E. Fraser, pers. comm.), indicating that the mechanisms underlying spinal cord generation are conserved between higher vertebrates. Once cells leave the stem zone they enter the forming neural tube and here neuronal differentiation and ventral patterning commence.

Numerous studies have established that fibroblast growth factor (FGF) signaling is required for the genera-

${ }^{1}$ Corresponding author.

E-MAIL k.g.storey@dundee.ac.uk; FAX 44-1382-345386.

Article published online ahead of print. Article and publication date are

at http://www.genesdev.org/cgi/doi/10.1101/gad.357705. tion of the vertebrate trunk and some progress has been made in the identification of FGF-regulated tissues within this region. FGFs are expressed in the stem zone and are also presented by neighboring tissues, the primitive streak, and the caudal paraxial mesoderm (Diez del Corral and Storey 2004). FGF signaling is required to inhibit onset of neuronal differentiation and ventral patterning genes in the stem zone (Bertrand et al. 2000; Diez del Corral et al. 2002, 2003). Furthermore, FGF signaling serves to retain cells within this region, as cells lacking such signals quickly move into the neural tube (Mathis et al. 2001). Recent work has established that a balance between opposing FGF signals in the stem zone region and retinoic acid (RA) signals provided by more rostrally located somitic mesoderm controls differentiation onset and segmentation in the extending body axis (Diez del Corral et al. 2003). While RA drives differentiation in part by inhibiting Fgf8 expression, FGF signaling inhibits retinoid synthesis and thereby helps to preserve the precursor cell pool that forms the stem zone (Diez del Corral et al. 2003). FGF signaling thus regulates multiple activities in the stem zone region, maintaining an undifferentiated cell state that must involve continued cell cycling and also the cohesion of the stem zone cell population; however, little is known about how FGF mediates these activities. 
Notch signaling is another pathway that regulates the differentiation status of cells in many contexts (Lewis 1998; Artavanis Tsakonas et al. 1999; Lai 2004). The trans-membrane receptor Notch is activated by binding of the Delta or Serrate ligand presented by an adjacent cell; this triggers cleavage of the intracellular domain of Notch, which then translocates to the nucleus together with the transcription factor Suppressor of Hairless $\mathrm{SuH} /$ RBP-Jk and there activates target genes, such as Hairy/ Hes basic helix-loop-helix (bHLH) factors (Artavanis Tsakonas et al. 1999). Notch signaling is best known for its role in the cell selection process, lateral inhibition (Simpson 1997; Lewis 1998; Schweisguth 2004). Within the vertebrate neuroepithelium this mechanism operates to regulate neuron production; Delta1, expressed by individual cells that are differentiating into neurons, stimulates Notch signaling and Hes gene expression in neighboring cells, which are thereby inhibited from differentiating and continue to proliferate (Chitnis et al. 1995; Henrique et al. 1995, 1997a; Lewis 1996). The phenotypes of mice with loss-of-function mutations in Notch pathway genes (Kageyama et al. 1997; Yoon and Gaiano 2005) support these initial results in frog and chick embryos and similar findings have been obtained in studies of neuroepithelial stem cells in vitro. These data indicate a requirement for Notch signaling to maintain these cells and to enhance their self-renewal properties by inhibiting differentiation (Nakamura et al. 2000; Hitoshi et al. 2002, 2004).

There is some evidence that Notch signaling is also active in the chick stem zone. FGF signaling maintains expression of stem zone-specific genes such as Sax1 and cash4, a chick homolog of Drosophila achaete-scute complex proneural genes that encode a bHLH transcription factor (Henrique et al. 1997b; Storey et al. 1998; Bertrand et al. 2000; Diez del Corral et al. 2002). Misexpression of cash 4 in heterologous contexts in the fly and frog embryo demonstrates that cash4 retains the transcriptional specificity that mediates proneural activity in the fly and can function as a proneural gene in a vertebrate embryo (Henrique et al. 1997b). In Drosophila, achaete-scute genes directly promote expression of Delta (Hinz et al. 1994; Kunisch et al. 1994; Heitzler et al. 1996) and a similar regulatory relationship has been demonstrated between vertebrate proneural gene homologs and Delta1 expression in differentiating neuroepitheluim (Chitnis and Kintner 1996; Fode et al. 1998; Casarosa et al. 1999; Cau et al. 2002). The endogenous function of cash4 in the chick stem zone, however, has yet to be elucidated, but these findings raise the possibility that cash4 promotes Delta expression in the stem zone.

Notch1 expression is detected in the neuroepitheluim commencing at Hamburger and Hamilton stages 7-8 (HH7-8) (Henrique et al. 1995; Caprioli et al. 2002), and a number of Hes5 family bHLH transcription factors, established targets, and effectors of Notch signaling in the neural tube, are also expressed in the stem zone (Fior and Henrique 2005). These observations therefore suggest that Notch signaling is active in the chick stem zone and may be promoted downstream of FGF. Further- more, the neural phenotype in Notch pathway mutant mice involves precocious neuronal differentiation and loss of neural progenitors/stem cells, but strikingly is also accompanied by truncation defects in mice lacking RBP-Jk, Presenilin1 and Presenilin2, and just Presenilin 1 (de la Pompa et al. 1997; Shen et al. 1997; Wong et al. 1997; Donoviel et al. 1999; Herreman et al. 1999) consistent both with a failure of lateral inhibition in the neural tube, but also with a possible role for the Notch pathway in maintaining the neural precursor pool in the stem zone.

Here we reveal that Delta1 is expressed in a broad and uniform domain in the chick stem zone, prior to the establishment of lateral inhibition in the differentiating neuroepithelium. We demonstrate that Notch signaling is active within this cell population and investigate the regulation and function of this pathway in the stem zone.

\section{Results}

Spinal cord stem zone cells experience Notch signaling

Examination of Delta1 expression in serial sections of the segmenting chick embryo reveals that this gene is expressed not only in nascent neurons adjacent to somites, but is also present in a distinct uniform domain in epiblast cells next to the anterior primitive streak (Fig. 1A-E). Using cell labeling techniques we (and others) have shown previously that cells in this region progressively give rise to the entire spinal cord (Brown and Storey 2000) and studies at later stages indicate that this region behaves as a stem zone (Mathis et al. 2001). Consistent with this activity we find that these Delta1 positive cells are mitotically active, as indicated by their incorporation of BrdU following only a brief ( $1 \mathrm{~h}$ ) exposure (Fig. 1F-F"). This contrasts with individual Delta1expressing cells located in the neural tube flanked by somites, which have left the cell cycle (Henrique et al. 1995) (Fig. 1G-G").

Delta1 expression in the stem zone is accompanied by that of its receptor Notch1 (Henrique et al. 1995; Caprioli et al. 2002), and by the expression of Hes5-1, a known target of Notch signaling (Fig. 1H-L; Fior and Henrique 2005), and these observations suggest that the Notch pathway is active in stem zone cells. To test this possibility, Notch signaling was blocked by misexpression of a dominant-negative Delta1 construct (DnDeltaIRES-GFP, which works cell autonomously) (Sakamoto et al. 2002, see Discussion) directly into stem zone cells (Fig. 1M). gfp-positive cells were then assessed for Hes5-1 expression $16 \mathrm{~h}$ later (Fig. 1M). Hes5-1 is expressed heterogeneously within its domain, but is absent in most cells expressing DnDelta, while cells expressing a control gfp-only vector can coexpress Hes5-1 (Fig. 1N-P). These findings indicate that cells in the stem zone normally experience Notch signaling and raise the possibility that the Notch pathway acts within this cell group to maintain its undifferentiated state. We therefore next addressed the role of Notch signaling in this cell population, assessing how such signaling is regulated by both 


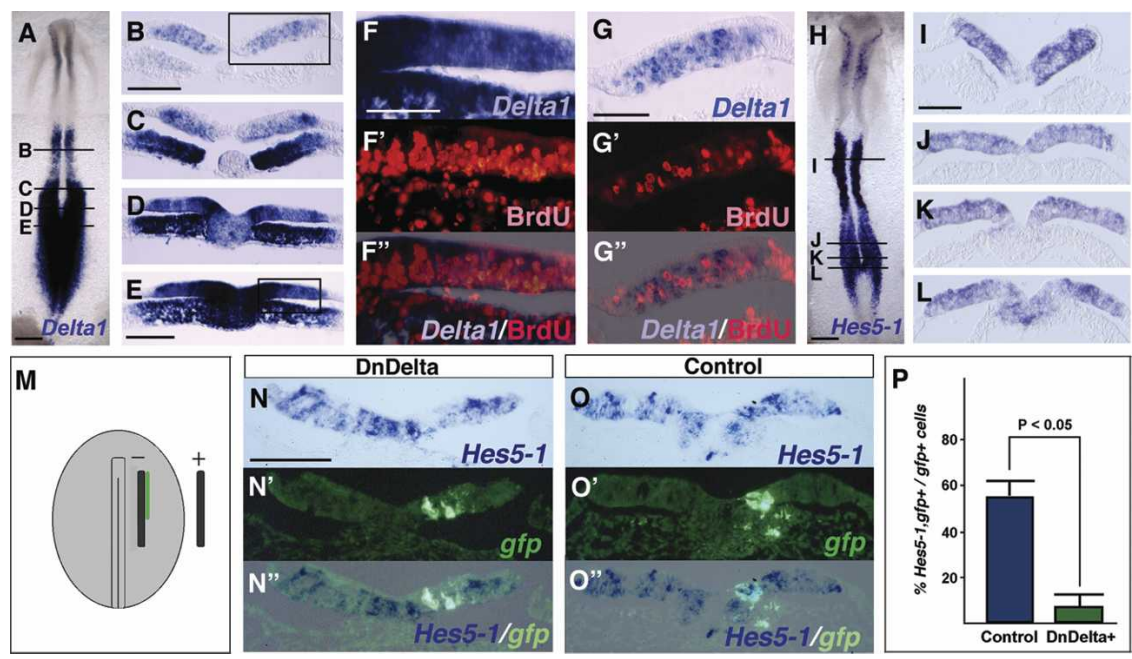

Figure 1. Stem zone cells experiencing Notch signaling are mitotically active. $(A-$ E) Delta1 at HH8 stage $(A)$ and in transverse sections (TS) $(B-E)$. (B) Closing neural tube. $(C)$ Transition zone. $(D)$ Hensen's node level. (E) Stem zone. (F) Higher magnification of boxed region in $E$. $\left(F^{\prime}\right) \mathrm{BrdU}$ in the same section. $\left(F^{\prime \prime}\right)$ Merged Delta1/BrdU image. $(G)$ Higher magnification of boxed region in $B .\left(G^{\prime}\right) \mathrm{BrdU}$ in the same section. $\left(G^{\prime \prime}\right)$ Merged Delta1/BrdU image. $(H-L)$ Hes5-1 at $\mathrm{HH} 8+(H)$ and in TS $(I-L) .(M)$ $\mathrm{HH} 4$ embryo indicating placement of electrodes and DNA solution (green) for direct targeting of stem zone cells. $\left(N-N^{\prime \prime}\right)$ Stem zone-level TS of a DnDelta-IRES-GFP-expressing embryo. $(N)$ Hes5-1. $\left(N^{\prime}\right) g f p$-positive cells in the same section. $\left(N^{\prime \prime}\right)$ Merged image. $\left(O-O^{\prime \prime}\right)$ Control IRES-GFP-only-expressing embryo. Hes5-1 $(O)$ and $g f p$-positive $\left(O^{\prime}\right)$ cells in the same section. $\left(O^{\prime \prime}\right)$ Merged Hes5-1/gfp image. $(P)$ Frequency of Hes5-1 expression in gfp-positive cells obtained in DnDelta and control conditions. In controls, $55.3 \%$ (SD 6.6\%; 16 sections from three embryos; blue bar) of $g f p$-positive cells had Hes5-1 gene expression, while only 7.3\% (SD 5.5\%; 13 sections from three embryos; green bar) of gfp-positive cells expressed Hes5-1 in DnDelta transfected embryos. Bars: $A, H, 200 \mu \mathrm{m} ; B, E, I, N, 50 \mu \mathrm{m} ; F, G, 20 \mu \mathrm{m}$.

intrinsic and extrinsic factors and its effects on cell behavior in the stem zone.

\section{A stem zone-specific proneural gene, cash4, induces Delta 1}

Proneural genes promote Delta expression in flies and vertebrates, and so we assessed which proneural gene(s) are expressed at the right time and place to mediate Delta1 expression in the stem zone. Delta1 is initially restricted to the primitive streak but expands laterally into the adjacent stem zone epiblast as node regression commences from HH6-7 and is accompanied at this time by the spread of Notch1 expression into this region (Fig. 1D,E; Henrique et al. 1995; Caprioli et al. 2002). As noted above, this expansion of Delta1 nicely follows the onset of the proneural gene homolog cash 4 at $\mathrm{HH} 5$ in the stem zone region (Henrique et al. 1997b). We also compared cash4 expression at these stages with that of other key proneural gene homologs, the Neurogenin genes. Expression of neither Ngn1 nor Ngn2 prefigures Delta1 in the stem zone; Ngn1 first appears in neural tissue opposite somite 1 at $\mathrm{HH} 7$ (Fig. 2A,B), while Ngn2 commences at $\mathrm{HH} 8$ (Fig. 2C) and only in the lateral edges of the open neural plate. In fact, these Ngn expression patterns appear complementary to that of cash4 (Fig. 2D-J; Henrique et al. 1997b), which is clearly the best candidate proneural gene for regulation of Delta1 in the stem zone.

To test whether cash 4 can promote Delta1 expression, the full cash4 coding region was cloned into an expression vector containing an IRES-GFP sequence. This was then introduced into HH9-10 closing neural tube (Fig. 3A) where cash4 is still expressed, but where Delta1 expression is dispersed rather than uniform. We first ascertained that this vector drives both the GFP and CASH4 protein using antibodies raised against GFP and CASH4
(Fig. 3B-D"). We then assessed the effect of ectopic maintenance of CASH4 in the elongating spinal cord. In the majority of cases we found that cash 4 misexpression promotes Delta1 expression (14 out of 17 embryos) after $8 \mathrm{~h}$ incubation, while a control empty vector /containing only an IRES-GFP sequence) does not elicit Delta1 (10 embryos) (Fig. 3E-F"). We next generated constructs that allow us to test whether CASH4 works as an activator or a repressor in this context. Misexpression of cash4 fused to the activator domain VP16 (cash4VP16) promotes Delta1 expression (12 out of 13 embryos), while cash4 fused to the repressor domain of the Engrailed protein (cash4EnR) does not elicit ectopic Delta1 (11 embryos) (Fig. 3G-H"). These findings indicate that cash4 works as an activator to promote Delta1 expression.

One interpretation of this finding is that cash 4 works in this neural tube assay by inducing expression of proneural genes, which then induce Delta1. Surprisingly, however, $8 \mathrm{~h}$ after cash 4 misexpression both $N g n 1$ and Ngn2 transcripts are suppressed (Ngn1, six out of eight embryos; Ngn2, four out of six embryos), while this is not observed with a control IRES-GFP-only vector (Ngn1, four out of four embryos; Ngn2, four out of four embryos) (Fig. 3I-L"). This absence of Ngn expression could indicate that cash 4 drives neuronal differentiation in this context and that it leads to only transient $N g n$ expression. We therefore next assessed whether cash 4 misexpression promotes Ngns after a shorter period of only $5 \mathrm{~h}$, (the time at which GFP first appears following introduction of cash4-IRES-GFP) (data not shown). However, Ngn levels are unaffected at this time $(N g n 1$, three out of three embryos; Ngn2, three out of three embryos) (data not shown). These findings therefore suggest that CASH4 does not promote Delta1 expression via induction of these proneural genes.

In addition, we found that cash4EnR expression in this 
Figure 2. Cash4 and Ngn2 are expressed in complementary domains in the extending neural axis. Ngn1 at $\mathrm{HH} 7(A)$ and $\mathrm{HH} 8(B) .(C) \mathrm{Ngn} 2$ at $\mathrm{HH} 8$. cash4 at $\mathrm{HH} 5+(D), \mathrm{HH} 8(E)$, and $\mathrm{HH} 9(F)$. CASH4 at $\mathrm{HH} 9$ seen in TS (indicated on a different embryo in $F$ ), in the last formed somite $(G)$, in the transition zone $(H)$, anterior to the Hensen's node $(I)$, and in the stem zone $(J)$. Bars: $A, D, 100 \mu \mathrm{m} ; B, F, 200 \mu \mathrm{m} ; G, 50 \mu \mathrm{m}$. (Arrowheads) Hensen's node.
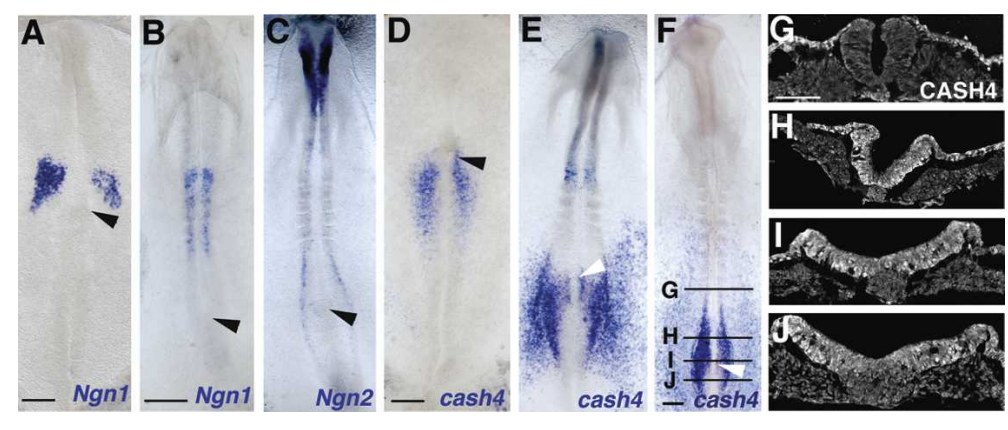

same assay leads to $\mathrm{Ngn} 1$ up-regulation (five out of five embryos) (Fig. 3M-M"). This suggests that CASH4 also works as a transcriptional activator to suppress $\mathrm{Ngn1}$ and that cash4EnR works as a dominant-negative construct that blocks CASH4 function. Utilizing this construct, we then assessed whether CASH4 is required for Delta1 expression in the stem zone. To achieve this we introduced constructs into the epiblast lateral to the primitive streak at $\mathrm{HH} 4$ and cultured embryos for $10 \mathrm{~h}$ (Fig. 4A). Cells in this region move medially and are included in the stem zone as demonstrated by the location of IRES-GFP-only transfected cells (Fig. 4B-C'). By targeting these cells we aimed to block CASH4 function as this gene begins to be expressed. The majority of embryos expressing the control vector had normal levels of Delta1 expression (seven out of 10 embryo) (Fig. 4C, $\mathrm{C}^{\prime}$ ) and this clearly contrasts with the loss of Delta1 expression in stem zone epiblast cells expressing cash4EnR in most cases (five out of seven embryos) (Fig. 4D-F). Further, in cash4EnR-expressing embryos, Delta1 loss is restricted to the stem zone epiblast, while $g f p$-positive cells located centrally within the primitive streak where cash4 is not expressed continue to express Delta1 (Fig. 4D-F). Cell counts were performed to quantify the difference between typical control IRES-GFP and cash4EnR-expressing cells in the stem zone and in the primitive streak (Fig. 4F). Together these findings suggest that cash 4 is required for Delta1 expression in the stem zone.

\section{FGF signaling is required for expression of Delta1} and the proneural gene cash 4

To establish the regulatory relationship between FGF and Notch signaling in the stem zone, we misexpressed a DnFGFR1-eYFP construct in epiblast cells lateral to the primitive streak at $\mathrm{HH} 4$ and assessed Delta1 expression $10 \mathrm{~h}$ later. Loss of Delta1 was observed in all cases (nine out of nine embryos) (Fig. 4G- $\mathrm{H}^{\prime \prime}$ ) with transcripts absent in the majority of DnFGFR1-expressing cells (Fig. 4I), while most cells transfected with the IRES-GFP-only vector continue to express Delta1 (IRES-GFP controls as above) (Fig. 4I). This finding places FGF signaling upstream of Delta1 expression in the stem zone. Interestingly, we also found a small number of DnFGFR1 cells located within the primitive streak and noticed that these cells also lack Delta1 (Supplementary Fig. 1).

It has been shown previously that FGF signaling can ectopically maintain expression of the proneural gene cash4, (Henrique et al. 1997b; Storey et al. 1998; Bertrand et al. 2000; Diez del Corral et al. 2002) and as cash4 can induce Delta1, we next assessed whether FGF signaling is required for cash4 expression in the stem zone. Misexpression of DnFGFR in this cell population for $10 \mathrm{~h}$ leads to loss of cash4 (four out of four embryos) (Fig. 4J-L") while control, gfp-only transfected cells coexpress cash 4 and $g f p$ in all cases (four embryos) (Fig. $4 \mathrm{~J}, \mathrm{M}-\mathrm{N}^{\prime \prime}$ ). Together these data define the regulatory relationship between FGF and Notch signaling and indicate that FGF acts upstream of cash4, which is in turn required for Delta1 expression in the stem zone.

Notch signaling does not regulate cell movement out of the stem zone, but maintains proliferation within this cell group

Previous work has shown that cells made deaf to FGF signaling are more rapidly displaced out of the stem zone than GFP-only-expressing cells, and so FGF helps to regulate cohesion of the stem zone cell population (Mathis et al. 2001). To see whether Notch signaling in the stem zone is contributing to this regulatory mechanism, we compared cell movement out of the stem zone following loss of FGF or Notch signaling. DnFGFR1 or DnDelta constructs were misexpressed in the stem zone at HH4-6 and embryos were assessed $24 \mathrm{~h}$ later (see Fig. 1M). As shown previously, cells expressing DnFGFR1 leave the stem zone region and are located in the neural tube (seven out of seven embryos), but those expressing DnDelta (seven out of seven embryos) or a control IRESGFP-only construct (five out of five embryos) are distributed more evenly along the rostro-caudal axis and many cells are still located in the stem zone (Fig. 5). This demonstrates that Notch signaling does not account for the ability of FGF to regulate movement of cells out of the stem zone and into the forming neural tube.

Cell proliferation is required to maintain the stem zone cell population and so we next assessed whether Notch signaling is necessary for this process by examining incorporation of BrdU in cells lacking Notch signaling. DnDelta-IRES-GFP was expressed in the HH4-6 stem zone (see Fig. $1 \mathrm{M}$ ) and embryos examined $16 \mathrm{~h}$ later following exposure to BrdU for the final hour. Most stem zone cells expressing DnDelta do not incorporate BrdU (Fig. 6A-F,M), while many IRES-GFP-only transfected 


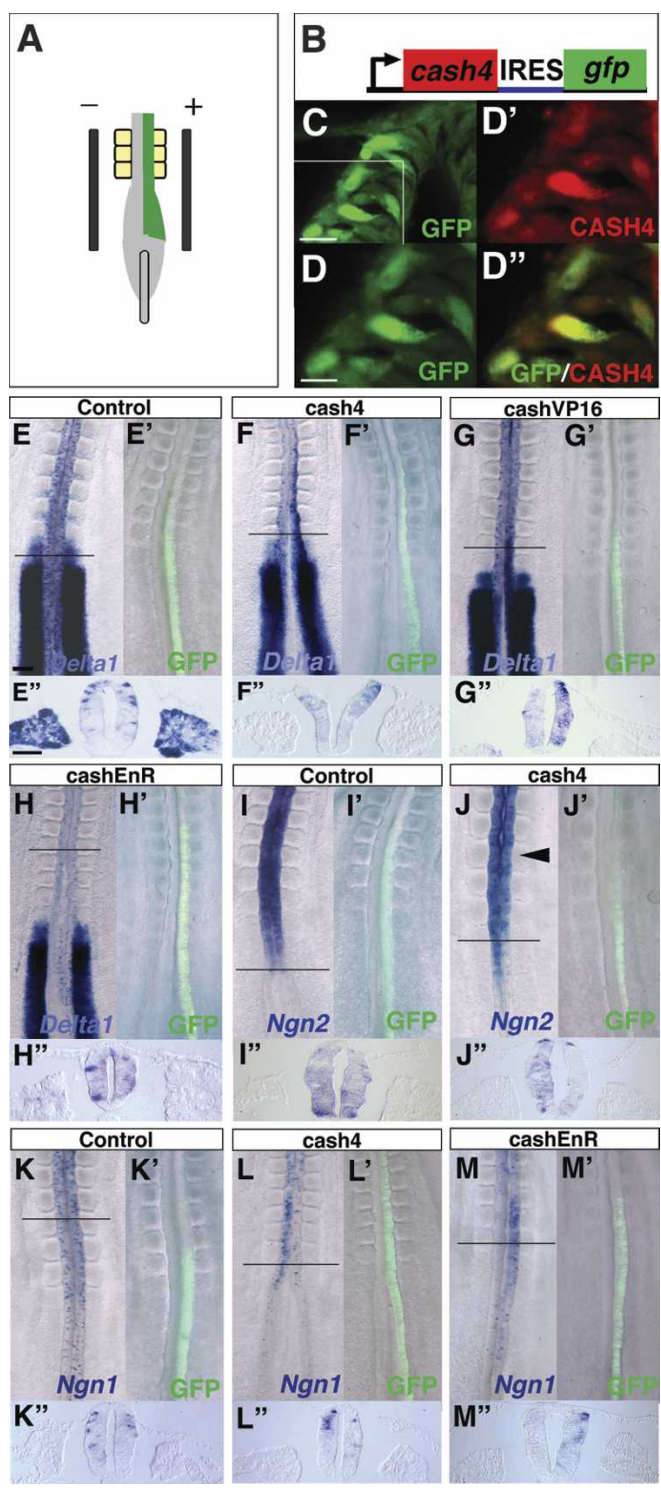

Figure 3. CASH4 works as an activator to induce Delta1. $(A)$ Electroporation at HH10. (B) cash4 expression vector (cash4IRES-GFP). (C) GFP-positive cells following misexpression of cash4-IRES-GFP in the neural tube. $\left(D-D^{\prime \prime}\right)$ Colocalization of GFP and CASH4 proteins. (D) Higher magnification of the boxed region in $C$. $\left(D^{\prime}\right)$ CASH4 detected with a CASH4 antibody in the same section. $\left(D^{\prime \prime}\right)$ Merged image shows CASH4 in the nuclei of the GFP-positive cells. $\left(E-M^{\prime \prime}\right)$ Misexpression experiments. In all cases, the first panel shows in situ of gene of interest, the second panel shows GFP localization prior to fixation, and the third panel shows TS through the region of misexpression indicated in the first panel. $\left(E-E^{\prime \prime}\right)$ Delta1 following control vector misexpression. $\left(F-F^{\prime \prime}\right)$ Delta1 following cash 4 misexpression. $\left(G-G^{\prime \prime}\right)$ Delta1 following cashVP16-IRES-GFP misexpression. $\left(H-H^{\prime \prime}\right)$ Delta1 following cashEnR-IRES-GFP misexpression. We saw no change in Delta1 expression (apparent asymmetry is due to compression of tissue in whole-mount prep). (I-I") $N g n 2$ following control vector misexpression. $\left(J-l^{\prime \prime}\right)$ Ngn2 following cash4-IRES-GFP misexpression. $\left(K-K^{\prime \prime}\right)$ Ngn1 following control vector misexpression. $\left(L-L^{\prime \prime}\right) N g n 1$ following misexpression of cash4-IRES-GFP. $\left(M-M^{\prime \prime}\right)$ Ngn1 following cashEnR-IRES-GFP misexpression. Bars: $C, 20 \mu \mathrm{m} ; D, 10 \mu \mathrm{m} ; E, 100 \mu \mathrm{m} ; E^{\prime \prime}, 50 \mu \mathrm{m}$. cells are labeled with this marker of S-phase progression (Fig. 6G-M). This indicates that Notch signaling is required for cell proliferation in the stem zone.

\section{Blocking Notch signaling is insufficient for neuronal differentiation}

As loss of Notch signaling blocks cell proliferation, it may also lead to precocious differentiation of cells in the stem zone. To assess this possibility the DnDelta construct was expressed in the stem zone at HH4-6 (see Fig. $1 \mathrm{M}$ ) and expression of NeuroM, a marker of newly born neurons (Roztocil et al. 1997; Diez del Corral et al. 2002) was examined $16 \mathrm{~h}$ later. NeuroM expression is normally confined to single cells within the neural tube flanked by somites and is never expressed in the stem zone (Diez del Corral et al. 2002). NeuroM transcripts were not detected in stem zone cells expressing DnDelta-IRES-GFP (eight out of eight embryos) (Fig. 6N-O") (the same result was also obtained by blocking Notch signaling by overexpression of DnSuH construct, two out of two embryos; data not shown). This finding is identical to that observed following expression of IRES-GFP-only control vector (nine embryos) (Fig. 6P-Q"). We also assessed whether loss of Notch signaling in the stem zone leads to expression of an earlier marker of neural differentiation, Ngn1. As with NeuroM, no Ngn1-positive cells were detected in the stem zone following misexpression of DnDelta1 or the control GFP-only construct in this region (five out of five embryos DnDelta1; five embryos IRES-GFP-only) (Supplementary Fig. 2). These findings indicate that loss of Notch signaling and cell cycle exit are not sufficient to promote neuronal differentiation in the stem zone.

\section{Discussion}

We have identified a new domain of uniform Delta1 expression localized in the spinal cord stem zone. These cells are mitotically active and transduce Notch signaling as indicated by the loss of the Notch effector gene Hes5-1 when Delta/Notch signaling is blocked. Delta1 expression in the stem zone is promoted by the proneural gene cash 4 and we further demonstrate that FGF signaling is required for cash 4 and Delta1 expression. This defines the regulatory cascade by which FGF promotes Notch signaling; FGF induces cash4, which promotes Delta1, which in turn mediates Notch signaling and expression of Hes5-1. Significantly, we show that Notch activity is in part responsible for FGF functions in the stem zone; it does not regulate movement of cells out of this region, but maintains proliferation within this cell population. Strikingly, as cells leave the stem zone we see that Delta1 expression resolves to single cells within the newly generated neuroepithelium. This is where lateral inhibition first begins to operate and this observation suggests that declining levels of FGF instigate the establishment of this mechanism in the neuroepithelium. Finally, we reveal that loss of Notch signaling is insufficient for neuronal differentiation in the stem 
Figure 4. FGF-dependent cash4 expression is required for Delta1 expression in the stem zone. (A) HH4 embryo indicating placement of electrodes and DNA solution (green) for targeting prospective stem zone cells in the lateral epiblast. $\left(B, B^{\prime}\right)$ Control IRES-GFP-only transfected embryo. Delta1 $(B)$ and $g f p\left(B^{\prime}\right)$ expression. $\left(C-C^{\prime \prime}\right)$ TS of Delta1. $\left(C^{\prime}\right)$ gfp. Delta1 $(D)$ and $g f p\left(D^{\prime}\right)$ expression following cashEnR misexpression. $\left(E-E^{\prime}\right)$ TS showing the loss of Delta1 expression in the stem zone. $(F)$ The proportion of $g f p$-positive cells expressing Delta1 in the stem zone and primitive streak. In cashEnR misexpressing embryos, $25.6 \%$ of $g f p$-positive cells express Delta1 (SD 14.8\%; 10 slides from three embryos; green bar). This is significantly lower than the proportion observed in the stem zone of control embryos $(99 \% \pm 1.4 \%, 13$ sections from three representative embryos; blue bar). In contrast, in the primitive streak the proportion of $g f p$-positive cells expressing Delta1 in cashEnR embryos $(90.4 \% \pm 1.72 \%)$ is not significantly different from that in controls $(93.3 \% \pm 1.3 \%) . \quad\left(G, G^{\prime}\right)$ DnFGFR $1-g f p$ misexpressing embryo. $\left(H-H^{\prime \prime}\right)$ TS and high-power views (boxed regions) showing loss of Delta1 expression in DnFGFR1$g f p$ positive cells in the stem zone. (I) The proportion of gfp-positive Delta1-expressing cells following DnFGFR1 misexpression $(32.9 \% \pm 12.1 \%$; nine sections from three embryos; green bar) is significantly lower than in control embryos (13 sections from three embryos; blue bar). (J) cash4 expression in the stem zone following DnFGFR1 misexpression. In control embryos, $72.1 \%$ (SD 2.1\%; 9 sections from two embryos;
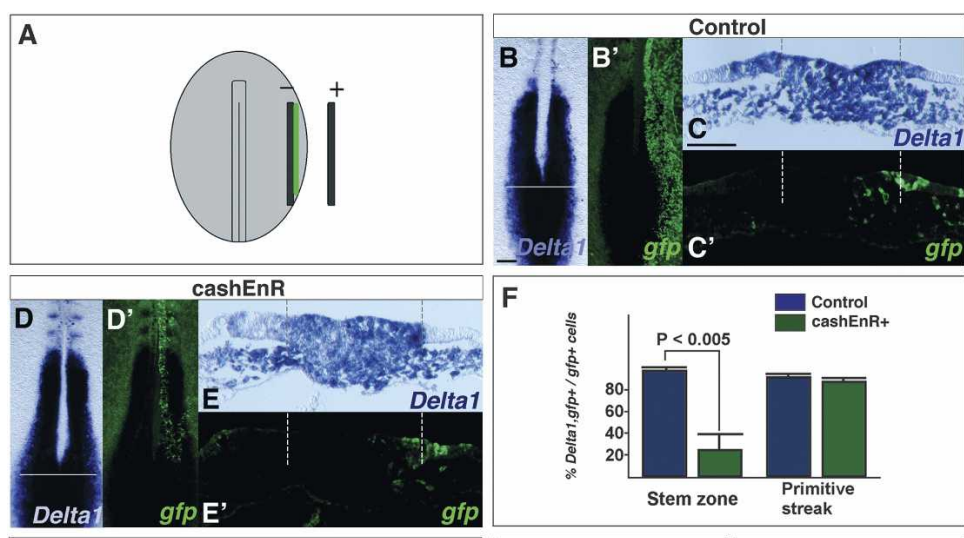

$\mathrm{F}$
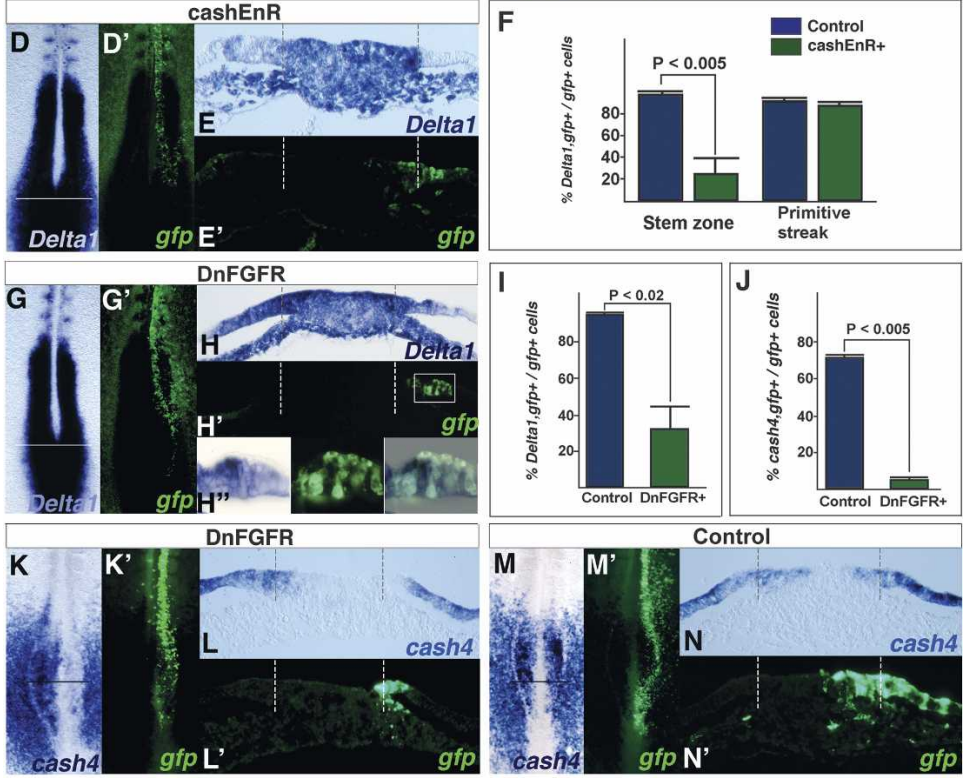

blue bar) of $g f p$-positive cells in the stem zone express cash4, whereas only $5.7 \%$ (SD $1.1 \%$; eight sections from two embryos; green bar) of cells in the stem zone have cash 4 expression in the DnFGFR 1 expression embryo. DnFGFR-misexpressing embryo $\left(K, K^{\prime}\right)$ and TS of cash4 $\left(L-L^{\prime}\right)$ in $g f p$-expressing cells. $\left(M, M^{\prime}\right)$ Control embryo. $\left(N-N^{\prime}\right)$ TS of cash 4 and $g f p$ expression. Dashed lines indicate the border between the primitive streak and the stem zone epiblast. Bars: $B, 100 \mu \mathrm{m} ; C, 50 \mu \mathrm{m}$.

zone. We propose that this reflects the requirement for retinoid signals provided by rostrally located somitic mesoderm, which we have shown previously attenuate FGF signaling and drive neuron production (for review, see Diez del Corral and Storey 2004).

\section{Notch and FGF signaling in the regulation of stem zone activity}

Within the vertebrate central nervous system Notch signaling is usually considered in the context of lateral inhibition, during which a single Delta1-expressing cell stimulates Notch signaling in its neighbors and thereby inhibits their differentiation. Here we describe a new situation in the stem zone, where uniform expression of Delta1 is observed. BrdU incorporation by Delta1-positive stem zone cells indicates that they are mitotically active and this contrasts with single Delta1-expressing cells in the neural tube, which have left the cell cycle. Further, we show that Notch signaling is required for the proliferation of stem zone cells. Together these findings suggest that uniform and high Delta1 expression results in uniform, mutually inhibitory, Notch signaling between stem zone cells, rather than localized stimulation of this pathway delivered by scattered Delta1-expressing cells, characteristic of lateral inhibition.
This Notch signaling context in the stem zone contrasts with that observed in other cell groups that express high levels of Delta1, such as epidermal stem cells (Lowell et al. 2000). These cells do not transduce Delta/ Notch signaling, but stimulate this pathway in neighboring cells at the group edge (Lowell et al. 2000). This may occur because cells expressing high levels of Notch ligand can make homodimers (Klueg and Muskavitch 1999), which can work in a dominant-negative fashion and lead to cell autonomous suppression of Notch signaling (Micchelli et al. 1997; Sakamoto et al. 2002). Interestingly, the DnDelta construct that we used appears to work by enhancing this cell autonomous inhibition of Notch signaling (Sakamoto et al. 2002). Our finding that this construct suppresses the Notch target gene Hes5-1 in stem zone cells thus suggests that these cells do not normally experience such a cell autonomous inhibition mechanism and clearly demonstrates that Notch signaling is normally active within stem zone cells.

FGF signaling is required to maintain the cohesiveness of the stem zone, as attenuation of this pathway drives cells out of this domain and into the neural tube (Mathis et al. 2001) and Notch signaling also regulates cohesion of cell groups in a variety of contexts (Lowell et al. 2000; Pourquie 2000). However, we found that cells expressing DnDelta are still able to stay in the stem zone, indicating 


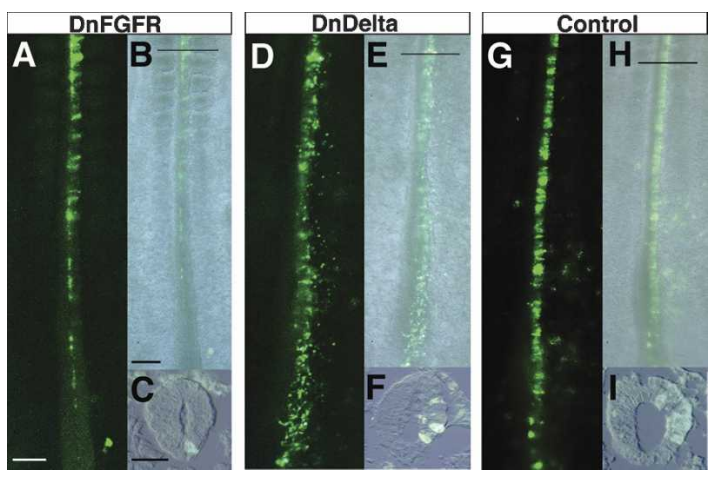

Figure 5. Notch signaling is not required to retain cells in the stem zone. Distribution of GFP-positive cells $24 \mathrm{~h}$ after misexpression of constructs in the stem zone at $\mathrm{HH} 4$ (imaged prior to fixation). (A) DnFGFR1-IRES-GFP-expressing cells. (B) Merged bright-field/GFP image. (C) TS of GFP cells in the neural tube. (D) DnDelta-IRES-GFP-expressing cells. (E) Merged brightfield/GFP image. $(F)$ TS of GFP cells in the neural tube. $(G)$ Control IRES-GFP-expressing cells. $(H)$ Merged bright-field/ GFP image. (I) TS. Bars: $A, B, 100 \mu \mathrm{m} ; C, 50 \mu \mathrm{m}$.

that Notch signaling does not mediate this FGF activity in this context. FGF has also been shown to act upstream of Notch signaling to maintain proliferation and the undifferentiated state of a number of stem cell populations, including neural and dental stem cells (Harada et al. 1999; Hitoshi et al. 2002; Yoon et al. 2004). We show here that FGF signaling is required for the broad expression of Delta1 in the stem zone, which we propose then leads to a state of mutual inhibition. This regulatory relationship differs from the action of FGF within a neuroepithelium in which lateral inhibition is operating, as here FGF up regulates Notch1 and suppresses Delta1 expression, which most likely represents differentiating neurons (Faux et al. 2001). The group of Delta1-expressing stem zone cells thus appears to represent a novel mode of Notch signaling operating during vertebrate neurogenesis, which is delivered between a group of FGF-dependent Delta/Notch-expressing cells and which acts to maintain the neural precursor cell pool that gives rise to the spinal cord.

\section{Notch signaling mediates body axis extension across species}

Cell populations equivalent to the chick stem zone in other vertebrates embryos express Notch pathway genes, and there is evidence that axis extension also relies on Notch signaling in these animals. Expression of Delta1 in a cell group adjacent to the organizer/anterior primitive streak is apparent in mouse and frog embryos (Bettenhausen et al. 1995; Ma et al. 1996; Beck and Slack 1998; Przemeck et al. 2003). Further, in the mouse, although a caudally located proneural gene has yet to be described, Hes5 is detected in the stem zone region and strikingly, is absent in mice lacking Notch1, RBP-Jk, or Presenilin1 and Presenilin2 (Figs. 3P, 4B,C; de la Pompa et al. 1997; Donoviel et al. 1999). As noted above, reduction of cell numbers within the neural tube of RBP-Jk and Presenilin1 single-knockout or Presenilin1 and Presenilin2 double-knockout mice is also accompanied by a truncation phenotype (de la Pompa et al. 1997; Shen et al. 1997; Wong et al. 1997; Donoviel et al. 1999; Herreman et al. 1999) supporting a role for the Notch pathway in the maintenance of the neural precursor cell pool in the stem zone. Furthermore, Notch signaling is required for tail bud outgrowth and specifically for regeneration of the spinal cord in the frog (Beck and Slack 2002; Beck et al. 2003). Although established later in development, the frog tailbud appears analogous to the stem zone of higher vertebrates (as well as homologous to the later forming tailbud). The Notch pathway thus plays a conserved role in the maintenance of the cell state necessary for extension of the neural axis.

Interestingly, while most stem zone cells form neural tissue, some cells located caudally within this region contribute to paraxial mesoderm (Catala et al. 1996; Brown and Storey 2000) and these cells coexpress panneural and early mesodermal genes as well as Delta1 (Kispert and Herrmann 1994; Kispert et al. 1995; Charrier et al. 1999; Delfino-Machin et al. 2005). Paraxial mesoderm is generated largely by cells located in the primitive streak, but the presence of some mesodermal precursors in the stem zone (for discussion, see DelfinoMachin et al. 2005), where Notch signaling is required for proliferation, suggests that the Notch pathway may also regulate generation of paraxial mesoderm. Consistent with this possibility we also observed loss of Delta1 transcripts in primitive streak cells expressing DnFGFR1.

\section{The stem zone as a persisting domain of mutual} inhibition

The spinal cord is generated progressively in a rostral to caudal sequence such that the temporal events of neurogenesis are spatially separated in the extending axis. Delta1 expression in a uniform domain is found in the caudal end of the stem zone, which contains cells that reside in the stem zone as it regresses, and which give rise to the caudal-most parts of the spinal cord (Brown and Storey 2000; Mathis et al. 2001). This uniform Delta1 expression resolves as cells leave this region, into individual cells within the neuroepithelium rostral to the primitive streak/node, which have been shown to be post-mitotic neuronal precursors (see Fig. 1A; Henrique et al. 1995). This temporal sequence is similar to that described within a proneural cluster in the fly epithelium (Simpson 1997). Here, all cells initially express both Notch and Delta and experience mutual inhibition. As differences in levels of Delta appear between cells, these differences are then reinforced by lateral inhibition and individual Delta-expressing cells are singled out. The caudal stem zone could therefore be considered a persisting proneural domain in which mutual inhibition operates. Cells near the edge of the broad Delta1 domain experience less FGF. As a result they become displaced 

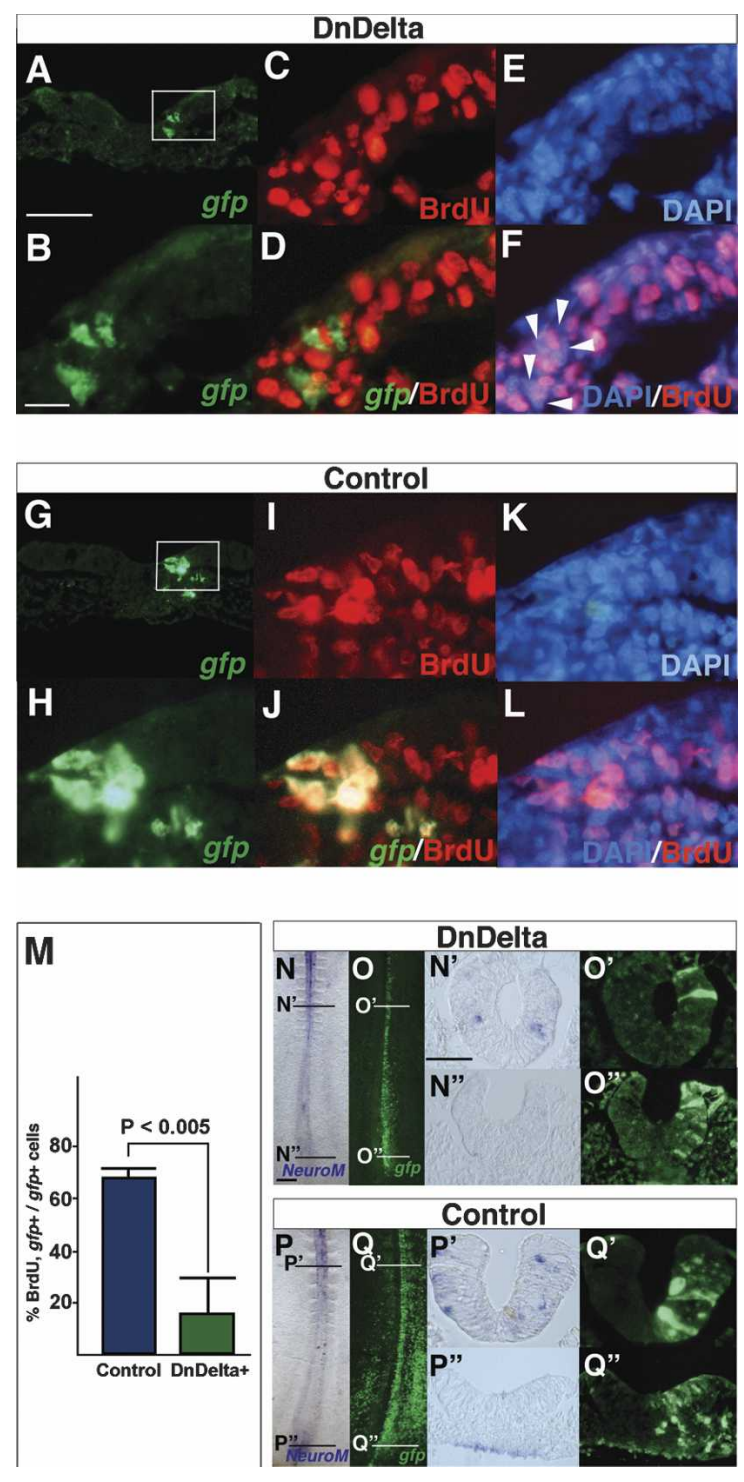

Figure 6. Notch signaling is required for proliferation of stem zone cells. (A) TS at stem zone level of DnDelta-IRES-GFPexpressing cells showing $g f p$. (B) Higher magnification of boxed region in $A .(C)$ BrdU-incorporating cells (red). (D) gfp/BrdU merged image. (E) DAPI. $(F)$ DAPI/BrdU merged image; note nuclei of $g f p$-positive cells (indicated by arrowheads) are BrdUnegative. $(G-L)$ TS at stem zone level in control IRES-GFP embryo. $(G) g f p$. (H) Higher magnification of boxed field in $G$. (I) BrdU-incorporating cells (red). ( $J)$ Merged $g f p / B r d U$ image. $(K)$ DAPI. (L) DAPI/BrdU merged image. ( $M$ ) In the stem zone, proportion of $g$ fp-expressing/BrdU-positive cells is $16.8 \%$ (SD $14.7 \%$; 13 sections from three embryos; green bar) in DnDeltaexpressing embryos. This is significantly lower than in control embryos $(68.3 \% \pm 3.0 \%$; seven sections from three embryos; blue bar). (N-Q") NeuroM expression following misexpression of DnDelta-IRES-GFP at HH4. (N) NeuroM in neural tube. TS of the neural tube $\left(N^{\prime}\right)$ and stem zone $\left(N^{\prime \prime}\right)$. (O) DnDelta-IRES-GFP cells in the same embryo as $N$, and in TS of the neural tube $\left(O^{\prime}\right)$ and stem zone $\left(O^{\prime \prime}\right)$. NeuroM in control IRES-GFP-expressing embryo $(P)$ and in TS of the neural tube $\left(P^{\prime}\right)$ and stem zone $\left(P^{\prime \prime}\right)$. (Q) $g f p$-only-expressing cells in the same embryo as $P$. TS of the neural tube $\left(Q^{\prime \prime}\right)$ and stem zone $\left(Q^{\prime \prime}\right)$. Bars: $A, 50 \mu \mathrm{m} ; B, 10 \mu \mathrm{m}$; $N, 200 \mu \mathrm{m} ; N^{\prime}, 50 \mu \mathrm{m}$. into the forming neuroepithelium where extensive cell mixing takes place (Mathis et al. 2001) and where they begin to lose cash4 and Delta1 expression. Slight differences in the levels of Notch signaling between cells in this transition zone may then lead to the establishment of lateral inhibition and the birth of neurons (Fig. 7).

It is not clear whether the first single Delta1-expressing cells retain expression or whether this is a new phase of Delta1 transcription is induced by the neurogenin genes, which now begin to be expressed in this tissue (Fig. 2A-C). As cash4 is induced by FGF and Ngns rely on Retinoid signaling supplied by adjacent differentiating paraxial mesoderm (Diez del Corral et al. 2003), this change in proneural gene expression reflects the switch from FGF to Retinoid signaling as differentiation progresses in the extending body axis. Importantly, these two pathways are mutually inhibitory in this context and FGF, by repressing onset of RA synthesis in the paraxial mesoderm and opposing RA activity in the neuroepithelium, maintains the stem zone as a Retinoid-free cell population (Diez del Corral et al. 2002, 2003). This may explain why blocking Notch signaling does not generate neurons in the stem zone, but does promote neuronal differentiation in the neural tube (le Roux et al. 2003; for review, see Yoon and Gaiano 2005). Indeed,

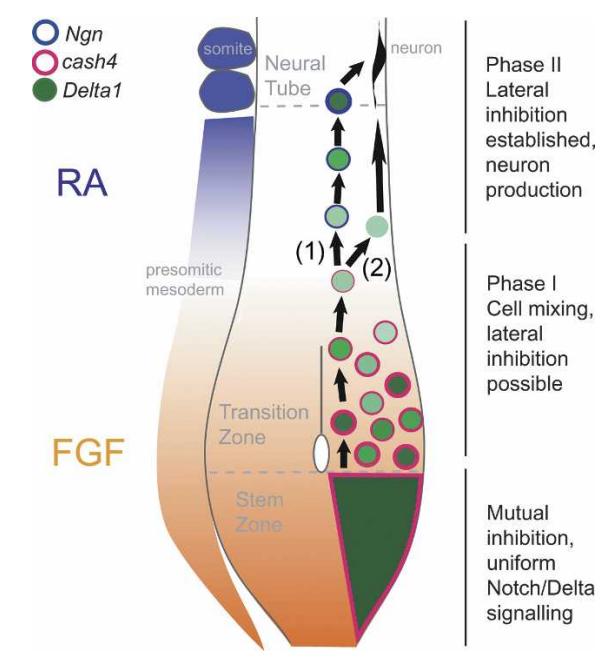

Figure 7. Model of neurogenesis progression in the extending axis. Stem zone cells all express Delta1 and experience mutual inhibition. Cells at the rostral edge of the stem zone experience less FGF and move out of this region into the forming neural tube (transition zone). Transition zone cells mix with recently arrived stem zone cells (Mathis et al. 2001), and as a result Delta1 expression begins to change from a uniform to a dispersed pattern. This is Phase I, and lateral inhibition is possible as differences between Notch signaling exist between neighboring cells. In Phase II, cells experience RA, and as a result FGF signaling declines (Diez del Corral et al. 2003) and hence cash4 and Delta1 levels are reduced. RA-dependent genes such as Ngns are now also expressed but are restricted to a few cells because lateral inhibition is already operating. Here Ngn expression promotes new Delta1 transcription leading regulated neuron production (1); some cells may also retain Delta1 expression from the stem zone and could differentiate into neurons (2). 
while asc class proneural genes are expressed in proliferating cells, atonal proneural gene homologs, such as the Ngns, drive cell cycle exit and differentiation of neuronal progenitors (for review, see Bertrand et al. 2002). Our findings thus help to dissect the role of Notch signaling in the nervous system, indicating that neuronal differentiation is not an automatic consequence of reduced Notch activity and that additional retinoid-dependent events are required (Fig. 7).

Iterative use of the Notch signaling pathway during the generation and patterning of a tissue has been described in other contexts, including the fly eye (Blair 1999; Baonza and Freeman 2001, 2005) and chick inner ear (Daudet and Lewis 2005). Our findings demonstrate that serial requirements for Notch signaling also underlie the generation of the spinal cord and identify a new context in which to study the transition from mutual to lateral inhibition.

\section{Materials and methods}

\section{In situ hybridization}

Standard methods for whole-mount in situ hybridization were used to detect expression of endogenous genes (Wilkinson and Nieto 1993) except for Ngn2, for which the hybridization step was performed at $70^{\circ} \mathrm{C}$ instead of $65^{\circ} \mathrm{C}$. Gfp transcripts were visualized with TSA plus fluorescence system (PerkinElmer Life Sciences) following manufacturer's instructions. Plasmids were kind gifts from Domingos Henrique (Faculdade de Medicina da Universidade de Lisboa, Lisboa, Portugal) (Delta1, Hes5-1), David Anderson (California Institute of Technology, Pasadena, CA) (Ngn1, Ngn2), and Mark Ballivet (University of Geneva, Geneva, Switzerland) (NeuroM).

\section{Immunocytochemistry}

Cash4 protein was detected with a cash4 antibody (1:50) raised in sheep (see below), using a biotin-conjugated anti-sheep secondary antibody (Jackson laboratories; 1:250) and Cy3-conjugated streptavidin (Jackson laboratories; 1:250) in sectioned tissue and imaged with a confocal microscope, TCS SPII (Leica). Incorporation of BrdU was detected using standard techniques (Gunhaga et al. 2000), following exposure of embryos in ovo or prepared in New culture to $1 \mu \mathrm{M}$ BrdU for a required period. BrdU was visualized with an anti-BrdU antibody (Roche; 1:20) and anti-mouse Cy3 conjugated antibody (Jackson laboratories; $1: 1000)$.

\section{CASH4 antiserum production}

A CASH4-CM construct was made containing 61-504 base pairs (bp) of cash4 sequence (Henrique et al. 1997b) corresponding to the bHLH and C-terminal region of the protein. This was cloned into pQE30 (Qiagen) and expressed in M15 Escherichia coli, which gave a $17-\mathrm{kDa}$ fusion protein with a $6 \mathrm{xHis}$ tag. This was purified on a NiNTA agarose column and eluted with $8 \mathrm{M}$ urea, $100 \mathrm{mM} \mathrm{NaH} \mathrm{PO}_{4}$, and $10 \mathrm{mM}$ Tris- $\mathrm{Cl}$ ( $\mathrm{pH}$ 5.9). One milliliter of the denatured protein at $1.25 \mathrm{mg} / \mathrm{mL}$ was sent for immunization into sheep at the Scottish antibody production unit. Second bleed antiserum was caprylic acid fractionated, resuspended in PBS, and dialyzed. Further purification was carried out by washing over CM protein bound to nitrocellulose and elution with $200 \mathrm{mM}$ glycine and $1 \mathrm{mM}$ EGTA (pH 2.5).
The antibody was then concentrated on a 10MWCO Microcon column (Millipore) and absorbed against HH stage 3 acetone powders prior to characterization on Western blots and by immunocytochemistry.

\section{Plasmid construction and in vivo electroporation}

The full ORF of the cash4 gene was cloned into the pBluescript vector. Part of the gene ( 309 nucleotides [nt]), including the DNA-binding site and HLH coding sequence, was subcloned and fused with the EnR repressor domain or VP16 activator domain coding sequence. Each form of the cash 4 gene was then transferred to the pEFBOS-IRES-GFP expression vector. The DnDelta construct (a kind gift from K. Katsube, Tokyo Medical and Dental University, Tokyo, Japan; Sakamoto et al. 2002) was subcloned into the pIRES2-EGFP expression vector (BD Biosciences). The DnSuH construct was kindly provided by D. Henrique. The DnFGFR1-eYFP vector was a kind gift from C. Weijer (University of Dundee, Dundee, UK) (Yang et al. 2002). As a control we used pEFBOS-IRES-GFP empty vector. Standard in ovo electroporation techniques were used on HH10 stage embryos (Fig. 4). Electroporation of $\mathrm{HH} 4$ stage embryos was preformed on embryos in New culture; embryos were placed dorsal up for electroporation and then replaced dorsal side down for subsequent culture (details available on request). For both electroporation strategies we used an INTRACEPT TSS10 dual pulse isolated stimulator (INTRACEL) and CUY610P1.5 parallel electrodes (NEPA GENE).

\section{Quantitative analysis}

Cell counts were carried out by superimposing bright-field (BCIP/NBT in situ hybridization signal) and $g f p /$ FITC images, and this was aided by nuclear labeling for BrdU or DAPI staining. The number of cells, sections, and embryos examined are indicated in the figure legends. The average percentage of cells expressing specific genes was obtained for each embryo and standard deviations were then calculated. $P$ values for statistical significance of differences between experimental and control samples were determined using Student's $t$-test.

\section{Acknowledgments}

We are grateful to Jennifer M. Brown and Julie Adam for preliminary studies misexpressing cash4, and to Anne Goriely for subcloning cash4 into an expression vector containing EnR when the KGS laboratory was based in the Department of Human Anatomy and Genetics, University of Oxford. We also thank Ruth Diez del Corral, Domingos Henrique, Miguel Maroto, and members of the KGS laboratory for valuable discussions and comments on the manuscript. Research in the KGS laboratory is supported by the MRC and KGS is an MRC Senior Research Fellow (G9900177).

\section{References}

Artavanis Tsakonas, S., Rand, M.D., and Lake, R.J. 1999. Notch signaling: Cell fate control and signal integration in development. Science 284: 770-776.

Baonza, A. and Freeman, M. 2001. Notch signaling and the initiation of neural development in the Drosophila eye. Development 128: 3889-3898.

- 2005. Control of cell proliferation in the Drosophila eye by Notch signaling. Dev. Cell 8: 529-539.

Beck, C.W. and Slack, J.M. 1998. Analysis of the developing 
Xenopus tail bud reveals separate phases of gene expression during determination and outgrowth. Mech. Dev. 72: 41-52. - 2002. Notch is required for outgrowth of the Xenopus tail bud. Int. J. Dev. Biol. 46: 255-258.

Beck, C.W., Christen, B., and Slack, J.M. 2003. Molecular pathways needed for regeneration of spinal cord and muscle in a vertebrate. Dev. Cell 5: 429-439.

Bertrand, N., Medevielle, F., and Pituello, F. 2000. FGF signaling controls the timing of Pax6 activation in the neural tube. Development 127: 4837-4843.

Bertrand, N., Castro, D.S., and Guillemot, F. 2002. Proneural genes and the specification of neural cell types. Nat. Rev. Neurosci. 3: 517-530.

Bettenhausen, B., Hrabe de Angelis, M., Simon, D., Guenet, J.L., and Gossler, A. 1995. Transient and restricted expression during mouse embryogenesis of Dll1, a murine gene closely related to Drosophila Delta. Development 121:24072418.

Blair, S.S. 1999. Eye development: Notch lends a handedness. Curr. Biol. 9: R356-R360.

Brown, J.M. and Storey, K.G. 2000. A region of the vertebrate neural plate in which neighbouring cells can adopt neural or epidermal cell fates. Curr. Biol. 10: 869-872.

Caprioli, A., Goitsuka, R., Pouget, C., Dunon, D., and Jaffredo, T. 2002. Expression of Notch genes and their ligands during gastrulation in the chicken embryo. Mech. Dev. 116: 161164.

Casarosa, S., Fode, C., and Guillemot, F. 1999. Mash1 regulates neurogenesis in the ventral telencephalon. Development 126: $525-534$.

Catala, M., Teillet, M.A., De Robertis, E.M., and Le Douarin, M.L. 1996. A spinal cord fate map in the avian embryo: While regressing, Hensen's node lays down the notochord and floor plate thus joining the spinal cord lateral walls. Development 122: 2599-2610.

Cau, E., Casarosa, S., and Guillemot, F. 2002. Mash1 and Ngn1 control distinct steps of determination and differentiation in the olfactory sensory neuron lineage. Development 129: 1871-1880.

Charrier, J.B., Teillet, M.A., Lapointe, F., and Le Douarin, N.M. 1999. Defining subregions of Hensen's node essential for caudalward movement, midline development and cell survival. Development 126: 4771-4783.

Chitnis, A. and Kintner, C. 1996. Sensitivity of proneural genes to lateral inhibition affects the pattern of primary neurons in Xenopus embryos. Development 122: 2295-2301.

Chitnis, A., Henrique, D., Lewis, J., Ish Horowicz, D., and Kintner, C. 1995. Primary neurogenesis in Xenopus embryos regulated by a homologue of the Drosophila neurogenic gene Delta. Nature 375: 761-766.

Daudet, N. and Lewis, J. 2005. Two contrasting roles for Notch activity in chick inner ear development: Specification of prosensory patches and lateral inhibition of hair-cell differentiation. Development 132: 541-551.

de la Pompa, J.L., Wakeham, A., Correia, K.M., Samper, E., Brown, S., Aguilera, R.J., Nakano, T., Honjo, T., Mak, T.W., Rossant, J., et al. 1997. Conservation of the Notch signaling pathway in mammalian neurogenesis. Development 124: 1139-1148.

Delfino-Machin, M., Lunn, J.S., Breitkreuz, D.N., Akai, J., and Storey, K.G. 2005. Specification and maintenance of the spinal cord stem zone. Development 132: 4273-4283.

Diez del Corral, R. and Storey, K.G. 2004. Opposing FGF and retinoid pathways: A signaling switch that controls differentiation and patterning onset in the extending vertebrate body axis. Bioessays 26: 857-869.
Diez del Corral, R., Breitkreuz, D.N., and Storey, K.G. 2002. Onset of neuronal differentiation is regulated by paraxial mesoderm and requires attenuation of FGF signaling. Development 129: 1681-1691.

Diez del Corral, R., Olivera-Martinez, I., Goriely, A., Gale, E., Maden, M., and Storey, K. 2003. Opposing FGF and retinoid pathways control ventral neural pattern, neuronal differentiation, and segmentation during body axis extension. Neuron 40: 65-79.

Donoviel, D.B., Hadjantonakis, A.K., Ikeda, M., Zheng, H., Hyslop, P.S., and Bernstein, A. 1999. Mice lacking both presenilin genes exhibit early embryonic patterning defects. Genes \& Dev. 13: 2801-2810.

Faux, C.H., Turnley, A.M., Epa, R., Cappai, R., and Bartlett, P.F. 2001. Interactions between fibroblast growth factors and Notch regulate neuronal differentiation. I. Neurosci. 21: 5587-5596.

Fior, R. and Henrique, D. 2005. A novel hes5/hes6 circuitry of negative regulation controls Notch activity during neurogenesis. Dev. Biol. 281: 318-333.

Fode, C., Gradwohl, G., Morin, X., Dierich, A., LeMeur, M., Goridis, C., and Guillemot, F. 1998. The bHLH protein NEUROGENIN 2 is a determination factor for epibranchial placode-derived sensory neurons. Neuron 20: 483-494.

Gunhaga, L., Jessell, T.M., and Edlund, T. 2000. Sonic hedgehog signaling at gastrula stages specifies ventral telencephalic cells in the chick embryo. Development 127: 32833293.

Harada, H., Kettunen, P., Jung, H.S., Mustonen, T., Wang, Y.A., and Thesleff, I. 1999. Localization of putative stem cells in dental epithelium and their association with Notch and FGF signaling. J. Cell Biol. 147: 105-120.

Heitzler, P., Bourouis, M., Ruel, L., Carteret, C., and Simpson, P. 1996. Genes of the Enhancer of split and achaete-scute complexes are required for a regulatory loop between Notch and Delta during lateral signaling in Drosophila. Development 122: $161-171$.

Henrique, D., Adam, J., Myat, A., Chitnis, A., Lewis, J., and Ish-Horowicz, D. 1995. Expression of a Delta homologue in prospective neurons in the chick. Nature 375: 787-790.

Henrique, D., Hirsinger, E., Adam, J., Le Roux, I., Pourquie, O., Ish Horowicz, D., and Lewis, J. 1997a. Maintenance of neuroepithelial progenitor cells by Delta-Notch signaling in the embryonic chick retina. Curr. Biol. 7: 661-670.

Henrique, D., Tyler, D., Kintner, C., Heath, J.K., Lewis, J.H., Ish Horowicz, D., and Storey, K.G. 1997b. Cash4, a novel achaete-scute homologue induced by Hensen's node during generation of the posterior nervous system. Genes \& Dev. 11: 603-615.

Herreman, A., Hartmann, D., Annaert, W., Saftig, P., Craessaerts, K., Serneels, L., Umans, L., Schrijvers, V., Checler, F., Vanderstichele, H., et al. 1999. Presenilin 2 deficiency causes a mild pulmonary phenotype and no changes in amyloid precursor protein processing but enhances the embryonic lethal phenotype of presenilin 1 deficiency. Proc. Natl. Acad. Sci. 96: 11872-11877.

Hinz, U., Giebel, B., and Campos-Ortega, J.A. 1994. The basichelix-loop-helix domain of Drosophila lethal of scute protein is sufficient for proneural function and activates neurogenic genes. Cell 76: 77-87.

Hitoshi, S., Alexson, T., Tropepe, V., Donoviel, D., Elia, A.J., Nye, J.S., Conlon, R.A., Mak, T.W., Bernstein, A., and van der Kooy, D. 2002. Notch pathway molecules are essential for the maintenance, but not the generation, of mammalian neural stem cells. Genes \& Dev. 16: 846-858.

Hitoshi, S., Seaberg, R.M., Koscik, C., Alexson, T., Kusunoki, S., 
Kanazawa, I., Tsuji, S., and van der Kooy, D. 2004. Primitive neural stem cells from the mammalian epiblast differentiate to definitive neural stem cells under the control of Notch signaling. Genes \& Dev. 18: 1806-1811.

Kageyama, R., Ishibashi, M., Takebayashi, K., and Tomita, K. 1997. bHLH transcription factors and mammalian neuronal differentiation. Int. J. Biochem. Cell Biol. 29: 1389-1399.

Kispert, A. and Herrmann, B.G. 1994. Immunohistochemical analysis of the Brachyury protein in wild-type and mutant mouse embryos. Dev. Biol. 161: 179-193.

Kispert, A., Ortner, H., Cooke, J., and Herrmann, B.G. 1995. The chick Brachyury gene: Developmental expression pattern and response to axial induction by localized activin. Dev. Biol. 168: 406-415.

Klueg, K.M. and Muskavitch, M.A. 1999. Ligand-receptor interactions and trans-endocytosis of Delta, Serrate and Notch: Members of the Notch signaling pathway in Drosophila. I. Cell Sci. 112: 3289-3297.

Kunisch, M., Haenlin, M., and Campos Ortega, J.A. 1994. Lateral inhibition mediated by the Drosophila neurogenic gene Delta is enhanced by proneural proteins. Proc. Natl. Acad. Sci. 91: 10139-10143.

Lai, E.C. 2004. Notch signaling: Control of cell communication and cell fate. Development 131: 965-973.

le Roux, I., Lewis, J., and Ish-Horowicz, D. 2003. Notch activity is required to maintain floorplate identity and to control neurogenesis in the chick hindbrain and spinal cord. Int. I. Dev. Biol. 47: 263-272.

Lewis, J. 1996. Neurogenic genes and vertebrate neurogenesis. Curr. Opin. Neurobiol. 6: 3-10.

. 1998. Notch signaling and the control of cell fate choices in vertebrates. Semin. Cell Dev. Biol. 9: 583-589.

Lowell, S., Jones, P., Le Roux, I., Dunne, J., and Watt, F.M. 2000. Stimulation of human epidermal differentiation by deltanotch signaling at the boundaries of stem-cell clusters. Curr. Biol. 10: 491-500.

Ma, Q., Kintner, C., and Anderson, D.J. 1996. Identification of neurogenin, a vertebrate neuronal determination gene. Cell 87: 43-52.

Mathis, L. and Nicolas, J.F. 2000. Different clonal dispersion in the rostral and caudal mouse central nervous system. Development 127: 1277-1290.

Mathis, L., Kulesa, P.M., and Fraser, S.E. 2001. FGF receptor signaling is required to maintain neural progenitors during Hensen's node progression. Nat. Cell Biol. 3: 559-566.

Micchelli, C.A., Rulifson, E.J., and Blair, S.S. 1997. The function and regulation of cut expression on the wing margin of Drosophila: Notch, Wingless and a dominant negative role for Delta and Serrate. Development 124: 1485-1495.

Nakamura, Y., Sakakibara, S., Miyata, T., Ogawa, M., Shimazaki, T., Weiss, S., Kageyama, R., and Okano, H. 2000. The bHLH gene hes 1 as a repressor of the neuronal commitment of CNS stem cells. J. Neurosci. 20: 283-293.

Pourquie, O. 2000. Skin development: Delta laid bare. Curr. Biol. 10: R425-R428.

Przemeck, G.K., Heinzmann, U., Beckers, J., and Hrabe de Angelis, M. 2003. Node and midline defects are associated with left-right development in Deltal mutant embryos. Development 130: 3-13.

Roztocil, T., Matter Sadzinski, L., Alliod, C., Ballivet, M., and Matter, J.M. 1997. NeuroM, a neural helix-loop-helix transcription factor, defines a new transition stage in neurogenesis. Development 124: 3263-3272.

Sakamoto, K., Ohara, O., Takagi, M., Takeda, S., and Katsube, K. 2002. Intracellular cell-autonomous association of Notch and its ligands: A novel mechanism of Notch signal modifi- cation. Dev. Biol. 241: 313-326.

Schweisguth, F. 2004. Notch signaling activity. Curr. Biol. 14: R129-R138.

Shen, J., Bronson, R.T., Chen, D.F., Xia, W., Selkoe, D.J., and Tonegawa, S. 1997. Skeletal and CNS defects in Presenilin1-deficient mice. Cell 89: 629-639.

Simpson, P. 1997. Notch signaling in development: On equivalence groups and asymmetric developmental potential. Curr. Opin. Genet. Dev. 7: 537-542.

Storey, K.G., Goriely, A., Sargent, C.M., Brown, J.M., Burns, H.D., Abud, H.M., and Heath, J.K. 1998. Early posterior neural tissue is induced by FGF in the chick embryo. Development 125: 473-484.

Wilkinson, D.G. and Nieto, M.A. 1993. Detection of messenger RNA by in situ hybridization to tissue sections and whole mounts. Methods Enzymol. 225: 361-373.

Wong, P.C., Zheng, H., Chen, H., Becher, M.W., Sirinathsinghii, D.J., Trumbauer, M.E., Chen, H.Y., Price, D.L., Van der Ploeg, L.H., and Sisodia, S.S. 1997. Presenilin 1 is required for Notch1 and DII1 expression in the paraxial mesoderm. $\mathrm{Na}$ ture 387: 288-292.

Yang, X., Dormann, D., Munsterberg, A.E., and Weijer, C.J. 2002. Cell movement patterns during gastrulation in the chick are controlled by positive and negative chemotaxis mediated by FGF4 and FGF8. Dev. Cell 3: 425-437.

Yoon, K. and Gaiano, N. 2005. Notch signaling in the mammalian central nervous system: Insights from mouse mutants. Nat. Neurosci. 8: 709-715.

Yoon, K., Nery, S., Rutlin, M.L., Radtke, F., Fishell, G., and Gaiano, N. 2004. Fibroblast growth factor receptor signaling promotes radial glial identity and interacts with Notch1 signaling in telencephalic progenitors. I. Neurosci. 24: 94979506. 


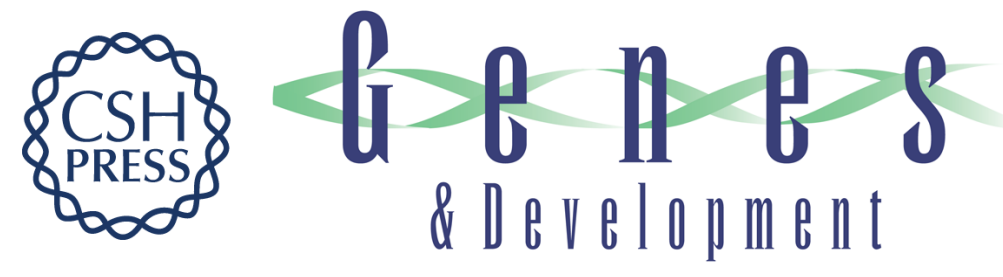

\title{
FGF-dependent Notch signaling maintains the spinal cord stem zone
}

\author{
Jun Akai, Pam A. Halley and Kate G. Storey
}

Genes Dev. 2005, 19:

Access the most recent version at doi:10.1101/gad.357705

Supplemental http://genesdev.cshlp.org/content/suppl/2005/11/14/gad.357705.DC1
Material

References This article cites 64 articles, 30 of which can be accessed free at: http://genesdev.cshlp.org/content/19/23/2877.full.html\#ref-list-1

License

Email Alerting Receive free email alerts when new articles cite this article - sign up in the box at the top Service right corner of the article or click here.

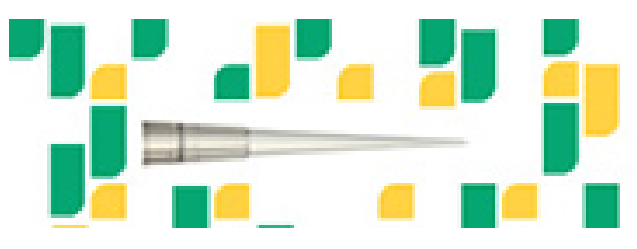

Focused on your science. 